\title{
Hop Excellence of Paths
}

\section{P. Getchial Pon Packiavathi, Balamurugan' R.B. Gnana Jothi}

\begin{abstract}
Excellent graphs introduced by [4] Dr.N. Sridharan and M.Yamuna, had been the motivation for many researchers and so many papers have been written as a result of deep and vast study of excellent graphs. [3] deals with a new type of excellence, namely hop excellence, based on hop domination closely related with distance-2 domination. A graph $G$ is said to be hop excellent if every vertex $u \in V$ belongs to a minimal hop domination set $\left(\gamma_{h}-s e t\right)$ of G. This paper aims to study hop excellence of paths.
\end{abstract}

Index Terms: Dominating Set, Excellent Graphs and Hop Dominating Set.

\section{INTRODUCTION}

In 2015, C.Natarajan and S.K. Ayyaswamy [1] introduced a new distance related domination parameter called the hop domination in graphs. A subset $S \subset V$ of a graph $G$ is a hop dominating set of $G$ if for every $v \in V-S_{v}$ there exists $u \in S$ such that $\mathrm{d}(\mathrm{u}, \mathrm{v})=2$. The minimum cardinality of a hop dominating set of $\mathrm{G}$ is called the hop domination number and is denoted by $\gamma_{h}(G)$. In [4] N. Sridharan and M. Yamuna introduced Excellent - Just Excellent - Very Excellent Graphs in 1980. A graph is said to be excellent if given any vertex $x$ then there is a $\gamma_{\text {-set of } \mathrm{G}}$ containing $x$. A graph $G$ is said to be just excellent if to each

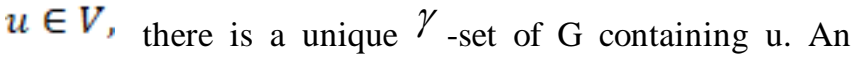
excellent graph $\mathrm{G}$ is said to be very excellent, if there is a $\gamma_{\text {-set } S \text { of } G \text { such that to each vertex }} u \in V-S_{\text {there exist }}$ a vertex $v \in S$ such that $(S-v) \cup\{u\}$ is a $\gamma_{\text {-set of }}$

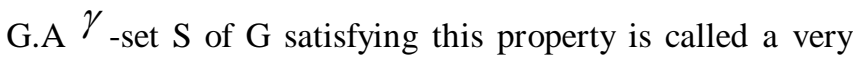

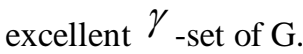

In [3] we introduced a new type of excellence. A graph G is said to be hop excellent if every vertex $u \in V$ belongs to a minimal hop dominating set $\left(\gamma_{h}-s e t\right)$ of G. Some families

Revised Manuscript Received on July 08, 2019.

P. Getchial Pon Packiavathi, Assistant Professor of Mathematics, V. V. Vanniaperumal College for Women, Virudhunagar, getchisaro@gmail.com

S. Balamurugan, Assistant Professor of Mathematics, Government Arts College, Melur, India.

R.B. Gnana Jothi, M.Phil Co-ordinator of Mathematics, V. V. Vanniaperumal College for Women, Virudhunagar, India of hop excellent graphs have been identified and some elementary properties of hop excellence are dealt with.

\section{Main Results}

Theorem :2.1

$P_{n}$, the path on n vertices is not hop excellent when $n \equiv 0,1,3,5(\bmod 6)$.

Proof:

$\gamma_{h}\left(P_{n}\right)=\left\{\begin{array}{lr}2 r & \text { if } n=6 r \\ 2 r+1 & \text { if } n=6 r+1 \\ 2 r+2 & \text { if } n=6 r+s, 2 \leq \mathrm{s} \leq 5\end{array}\right.$

Let $V\left(P_{n}\right)=\left\{v_{1}, v_{2}, \ldots . v_{n}\right\}$ and

$\mathrm{E}\left(P_{n}\right)=\left\{v_{i} v_{i+1} / 1 \leq i \leq n-1\right\}$

Case 1:

$\mathrm{n} \equiv 0(\bmod 6)$

Let $\mathrm{n}=6 \mathrm{r}$

Then $\gamma_{h}\left(P_{n}\right)=2 r=\frac{6 r}{3}$

Each vertex in a $\gamma_{h}$-set should hop dominate two vertices apart from it and no two vertices in

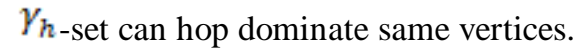

Hence pendant vertices as well as support vertices cannot appear in any $\gamma_{h \text {-set. }}$

Therefore Path with $\mathrm{n} \equiv 0(\bmod 6)$ are not hop excellent. Case 2:

$n \equiv 5(\bmod 6)$

Let $\mathrm{n}=6 \mathrm{r}+5$; Then $\gamma_{h}=2 \mathrm{r}+2$.

$6 \mathrm{r}+5=(2 \mathrm{r}+1) 3+2$

Let $\mathrm{D}$ be a $\gamma_{h}-$ set.

At most one vertex from $\left\{v_{1}, v_{2}, v_{n-1}, v_{n}\right\}$ can be present in D.

Suppose $v_{1} \in \mathrm{D}, v_{2} \notin_{\mathrm{D}}$

$v_{1}$ hop dominates $v_{3}$, $v_{2} \notin_{\mathrm{D}} \Rightarrow v_{4} \in_{\mathrm{D}}$.

$v_{3}$ is already hop dominated. If at all $v_{5} \in \mathrm{D}$, it hop dominates $v_{5}$ and $v_{7}$ only.

Hence $v_{5} \notin \mathrm{D}$.

$v_{4}$ hop dominates $v_{6}$, $v_{3}, v_{5} \notin_{\mathrm{D}} \Rightarrow v_{7} \in_{\mathrm{D}}$. 


\section{Hop Excellence of Paths}

Proceeding like this $v_{3 k+1} \in \mathrm{D}$ for $\mathrm{k}=0,1,2 \ldots$

$$
\begin{aligned}
v_{n-1}=v_{6 r+4} & =v_{3(2 r+1)+1} \in_{\mathrm{D}} \\
\Longrightarrow & \left.=v_{n-1} \notin_{\mathrm{D}}\right)
\end{aligned}
$$

Hence path with $n \equiv 5$ (mod 6$)$ is not hop excellent.

Case 3:

$$
\begin{aligned}
& \mathrm{n} \equiv 1(\bmod 6) \\
& \text { Let } \mathrm{n}=6 \mathrm{r}+1 ; \text { Then } \gamma_{h}\left(P_{n}\right)=2 \mathrm{r}+1 \\
& P_{n}=v_{1} v_{2} \ldots v_{6 r+1}
\end{aligned}
$$

Note that any hop dominating set of $P_{n}$ should contain at least two vertices from $\left\{v_{1}, v_{2}, v_{3}, v_{4}\right\}$.

Let $\mathrm{D}$ be any $\gamma_{h \text {-set of }} P_{n}$

$v_{1}, v_{3} \in D \Longrightarrow D \backslash v_{1}$ is also a hop dominating set.

$$
\Longrightarrow \Longleftarrow
$$

Similarly $v_{2}, v_{4}$ can not appear together in D.

Claim:

$v_{2}$ is a bad vertex

Suppose $v_{1} v_{2} \in D$. Then $v_{3}, v_{4} \notin D$

Let $D^{s}=D \backslash\left\{v_{1}, v_{2}\right\}$

$\left|D^{\prime}\right|=|D|-2=2 r-1$

Consider of $P_{n}^{\prime}=v_{5} v_{6} \ldots \ldots v_{6 r+1}$

Clearly $D^{z}$ is a hop dominating set of $P_{n}{ }^{z}$.

$$
\Rightarrow \vDash\left(\begin{array}{c}
\because l\left(P_{n}^{\prime}\right)=6 r+1-4=6 r-3=3(\bmod 6) \\
\Rightarrow \gamma_{h}\left(P_{n}^{\prime}\right)=2(r-1)+2=2 r
\end{array}\right)
$$

Suppose $v_{2}, v_{3} \in D$. Then $v_{1_{3}} v_{4} \notin D$

Let $D^{t}=D \backslash\left\{v_{2}, v_{3}\right\}$

$\left|D^{\prime}\right|=|D|-2=2 r-1$

If $v_{5} \in D^{x}$, then $D^{s}$ is a hop dominating set of $P_{n}^{\prime}=$

$v_{5} v_{6} \ldots \ldots v_{6 r+1}$

$\Longrightarrow \Longleftarrow$

If $v_{5} \notin D^{g}, D^{y}$ is a hop dominating set of $P_{n}{ }^{n}=$

$v_{6} v_{7} \ldots \ldots v_{6 r+1}$

$l\left(P_{n}^{m}\right)=6 r+1-5=6 r-4=6(r-1)+2$

$$
\Rightarrow \gamma_{h}\left(P_{n}^{m}\right)=2(r-1)+2=2 r
$$

$\Longrightarrow \Longleftarrow$

Therefore $v_{2}$ can not appear in any $\gamma_{h}-$ set and so $v_{2}$ is a bad vertex.

Hence path with $n \equiv 1_{(\bmod 6)}$ is not hop excellent.

Case 4:

$$
n \equiv 3(\bmod 6)
$$

Let $\mathrm{n}=6 \mathrm{r}+3$; Then $\gamma_{h}\left(P_{n}\right)=2 \mathrm{r}+2$.

$6 r+3=(2 r-1) 3+(3 \times 2)$

Claim:

$v_{5}$ is a bad vertex

If possible let D be a $\gamma_{h}-$ set of $P_{n}$ containing $v_{5}$.

Note that D should contain at least two vertices from

$\left\{v_{1}, v_{2}, v_{3}, v_{4}\right\}$

Case 1:
D contains two vertices from $\left\{v_{1}, v_{2}, v_{3}\right\}$

Consider $D^{\prime}=\mathrm{D} \backslash\left\{v_{1}, v_{2}, v_{3}\right\}$

Then $\left|D^{\prime}\right|=|D|-2$

Since $v_{5} \in D, D^{y}$ should be a $\gamma_{h}-$ set of $P_{n}^{f}=$

$v_{5} v_{6} \ldots v_{6 r+3}$

$l\left(P_{n}^{n}\right)=6 \mathrm{r}+3-4$

$=6 \mathrm{r}-1$

$\equiv 5(\bmod 6)$

By case 2 , for a path $P_{n}$ with $l\left(P_{n}\right) \equiv 5(\bmod 6)$, pendant vertex is a bad vertex.

So $v_{5} \notin D$

$\Longrightarrow \Longleftarrow$

Case 2:

Suppose $v_{1}, v_{4} \in D$, Then $v_{3}, v_{2} \notin D$.

Subcase 1:

$$
v_{6} \in D \text { or } v_{8} \in D
$$

Let $D^{\prime}=\mathrm{D} \backslash\left\{v_{1_{8}} v_{4}\right\}$

$$
\left|D^{\prime}\right|=2 \mathrm{r}
$$

$D^{\prime}$ is a hop dominating set of $P_{n}^{\prime}=v_{5} v_{6} \cdots v_{6 r+3}$

$l\left(P_{n}^{l}\right)=6 \mathrm{r}+3-4$

$$
\begin{aligned}
& =6 \mathrm{r}-1 \\
& \equiv 5(\bmod 6)
\end{aligned}
$$

$\gamma_{h}\left(P_{n}^{\prime}\right)=2(\mathrm{r}-1)+2=2 \mathrm{r}$

Hence $^{D^{\prime}}$ is a $\gamma_{h}-$ set of $P_{n}^{y}$

By case 2, pendant vertex of $P_{n}^{f}$ cannot be in $D^{f}$ $\Longrightarrow \Longleftarrow\left(\because v_{5} \in D^{\prime}\right)$

Subcase 2:

$v_{6} \notin D$ or $v_{8} \notin D$, then $v_{10} \in D$

If $v_{7} \in D_{0} D^{\prime \prime}=\mathrm{D} \backslash\left\{v_{1}, v_{4}, v_{5}\right\}$

$\left|D^{\prime \prime}\right|=2 \mathrm{r}-1$

$D^{\prime \prime}$ is a hop dominating set of $P_{n}^{n l}=v_{7} v_{8} \ldots v_{6 r+3}$

$$
\begin{aligned}
l\left(P_{n}^{m}\right) & =6 \mathrm{r}+3-6 \\
& =6 \mathrm{r}-3 \\
& =6(\mathrm{r}-1)+3 \\
& \equiv 3(\bmod 6)
\end{aligned}
$$

$\gamma_{h}\left(P_{n}^{I J}\right)=2(\mathrm{r}-1)+2=2 \mathrm{r}$

$$
\Longrightarrow \Longleftarrow\left(\approx\left|D^{n}\right|=2 r-1\right)
$$

If $v_{7} \notin D$ and $v_{9} \notin D$,

$D^{\prime \prime}$ is a hop dominating set of

$P_{n}^{y \prime \prime}=v_{9} v_{10} \ldots v_{6 r+3}$

$$
\begin{aligned}
l\left(P_{n}\right) & =6 \mathrm{r}+3-8 \\
= & 6 \mathrm{r}-5 \\
& =6(\mathrm{r}-1)+1 \\
& \equiv 1(\bmod 6)
\end{aligned}
$$

$\gamma_{h}\left(P_{n}^{m}\right)=2(\mathrm{r}-1)+1=2 \mathrm{r}-1$

Hence $^{D^{n}}$ is a $\gamma_{h}-$ set of $P_{n}^{m}$. 
By Case 3: support vertex cannot be in any $\gamma_{h}-$ set .

$\therefore v_{10} \notin D^{\prime \prime}$

$$
\Longrightarrow \Longleftarrow\left(\because v_{10} \in D^{n}\right)
$$

Hence path with $n \equiv 3(\bmod 6)$ is not hop excellent.

Theorem : 2.2

$P_{n}$, the path on $\mathrm{n}$ vertices is hop excellent when

$n \equiv 2(\bmod 6)$.

Proof:

$\mathrm{n} \equiv 2(\bmod 6)$

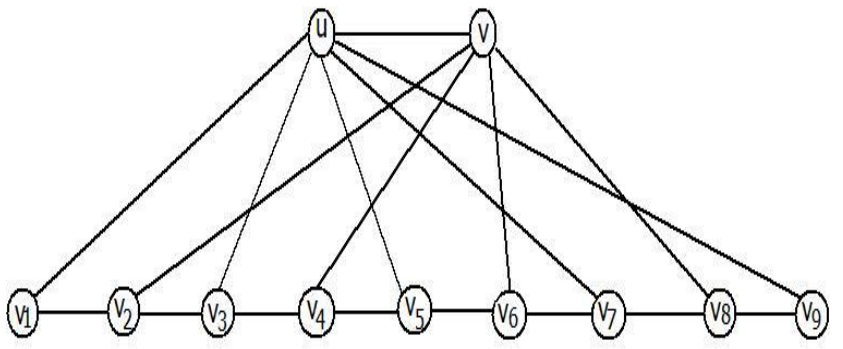

Let $\mathrm{n}=6 \mathrm{r}+2$, then $\gamma_{h}\left(P_{n}\right)=2 \mathrm{r}+2$.

Let $P_{n}=v_{1} v_{2} \ldots \ldots v_{6 r+2}$ and $P_{n}^{v}=v_{5} v_{6} \ldots \ldots v_{6 r+2}$

$l\left(P_{n}^{v}\right)={ }_{6 r}-2=6(\mathrm{r}-1)+4 \equiv 4(\bmod 6)$.

It has been proved that in [3], $P_{n}$ is hop excellent when $n \equiv$ 4( $\bmod 6)$.

$P_{n}^{y}$ is hop excellent and $\gamma_{h}\left(P_{n}^{\eta}\right)=2(\mathrm{r}-1)+2=2$ r.

Let $\mathrm{H}$ be any $\gamma_{h}-$ set of $P_{n}{ }^{\prime}$.

$\mathrm{H}^{\cup}\left\{v_{1}, v_{4}\right\}$ and $\mathrm{H} \cup\left\{v_{2}, v_{3}\right\}$ are $\gamma_{h}$ - sets of $P_{n}$.

$\left(\because \gamma_{h}\left(P_{n}\right)=2 \mathrm{r}+2\right)$

Hence path with $n \equiv 2(\bmod 6)$ is hop excellent.

Theorem: 2.3

Any path can be embedded in a hop excellent graph. Proof :

Let $P_{n}$ be a path of $\mathrm{n}$ vertices with

$V\left(P_{n}\right)=\left\{v_{1}, v_{2}, \ldots . . v_{n}\right\}$ and

$\mathrm{E}\left(P_{n}\right)=\left\{v_{i} v_{i+1} / 1 \leq i \leq n-1\right\}$.

Now construct a graph $\mathrm{H}$ as follows,

Let $\{\mathrm{u}, \mathrm{v}\}$ be a set disjoint with $V\left(P_{n}\right)$.

Let $\mathrm{V}(\mathrm{H})=V\left(P_{n}\right) \cup\{u, v\}$ and $\mathrm{E}(\mathrm{H})=$ $\mathrm{E}\left(P_{n}\right) \cup\left\{u v_{i} /\right.$ for odd $\left.i\right\} \cup\left\{v v_{i} /\right.$ for even $\left.i\right\}$

Clearly $P_{n}$ is an induced subgraph of $\mathrm{H}$.

For $1 \leq i \leq n, d\left(u, v_{i}\right)=\left\{\begin{array}{l}1 \text { if } i \text { is odd } \\ 2 \text { if } i \text { is even }\end{array}\right.$

$$
d\left(v, v_{i}\right)=\left\{\begin{array}{l}
1 \text { if } i \text { is even } \\
2 \text { if } i \text { is odd }
\end{array}\right.
$$

Note that $\{u, v\}$ is a hop dominating set of $\mathrm{H}$.

So the vertices $u$ and $v$ are hop excellent.

For any odd i, $\left\{v_{i}, u\right\}$ is a $\gamma_{h}$ set of $\mathrm{H}$.

For any even $\mathrm{i},\left\{v_{i}, v\right\}$ is a $\gamma_{h}$ set of $\mathrm{H}$.

Hence any $P_{n}$ is hop excellent graph.

Therefore $\mathrm{H}$ is hop excellent.

IIustration:

$H_{9}$

In $H_{9 y}$ The $\gamma_{h}$ - sets are

$\{\mathrm{u}, \mathrm{v}\}$,

$\left\{v_{1}, u\right\},\left\{v_{3}, u\right\},\left\{v_{5}, u\right\},\left\{v_{7}, u\right\},\left\{v_{9}, u\right\},\left\{v_{2}, v\right\},\left\{v_{4}, v\right\},\left\{v_{6}, v\right\},\left\{v_{8}, v\right\}$.

\section{Results \& Conclusion}

Paths have been completely categorized according to their behavior of being hop excellent. Embedding property has also been studied for paths. This work can be extended to some other families of graphs resulting to generalization of these results.

\section{REFERENCES:}

1. S.K. Ayyaswamy and C. Natarajan, Hop domination in graphs, Submitted to Discussions Mathematicae Graph Theory.

2. S.K. Ayyaswamy and C. Natarajan, Hop domination in graphs- II, An.St.Univ.Ovidius Constanta,Vol.23(2), 2015, 187-199 .

3. S. Balamurugan, R.B. Gnana Jothi and P.Getchial Pon Packiavathi, Hop Excellent Graphs, Mathematical Sciences International Research Journal Volume 6 Spl Issue, 2017, 275-279.

4. N. Sridharan and M. Yamuna, Excellent - just excellent - very excellent Graphs, Journal of Math. Phy. Sci., Vol.14, No.5, 1980, 471- 475.

5. [5] N. Sridharan and M. Yamuna, Excellent, just excellent and very excellent graphs, Ph.D, dissertation. Submitted to Alagappa University, Karaikudi, South India, December, 2003.

\section{AUTHORS PROFILE}

P. Getchial Pon Packiavathi, Assistant Professor of Mathematics, V. V. Vanniaperumal College for Women, Virudhunagar

S. Balamurugan, Assistant Professor of Mathematics, Government Arts College, Melur, Tamilnadu, India

R.B. Gnana Jothi, Computer Science, .Phil Co-ordinator of Mathematics, V. V. Vanniaperumal College for Women, Virudhunagar, India. 